\title{
Emissivity Measurements on Shape Memory Alloys
}

\author{
by Tadeu C. da Silva*, Marcus V. Costa Sá*, Edson P. da Silva* and Francisca C. da Silva** \\ * Univ. of Brasilia, Mechanical Engineering Dept., Faculty of Technology FT, 70910-900, Brasilia, Brazil, \\ tcastro@unb.br, marcuscsa@gmail.com,dasilva@unb.br \\ ** Federal University of Campina Grande, PPGEM, Campina Grande, PB, Brazil, cibeleproj@hotmail.com
}

\begin{abstract}
In many applications of Shape Memory Alloys, the most appropriate means and sometimes the only one to measure temperature is thermography, which relies on knowing the emissivity of the material. This paper aims to evaluate experimentally the behavior of the emissivity of a NiTi shape memory alloy as a function of temperature in order to investigate how the emissivity behaves during phase transformation and how it may impact the measured temperature. The emissivity of a $\mathrm{Ni}_{55} \mathrm{Ti}_{45}$ shape memory alloy was measured by means of active and passive infrared sensors in a spectral band of $8-14 \mu \mathrm{m}$ in the temperature range from 25 to $100^{\circ} \mathrm{C}$ under a vacuum of $3 \times 10^{-3} \mathrm{~Pa}$. The results show that the emissivity of the $\mathrm{Ni}_{55} \mathrm{Ti}_{45}$ shape memory alloy varied approximately $9 \%$ between fully martensitic and fully austenitic states.
\end{abstract}

\section{Introduction}

In the last decades, the use of intelligent materials has been intensified in a variety of mechanical systems [1-2]. Among those systems, the shape memory alloys (SMAs) show a great potential in the shape memory effect, especially equiatomic NiTi alloys, which can deform itself up to $8 \%$ and restore itself to its original shape, and then repeat the same operation a large number of times [3]. In certain applications such as the actors that involve important deformations, loads and low frequencies, the SMAs have a significant potential in relation to the traditional actors due to their high proportion of energy and silent performance [4]. Furthermore, those alloys show a thermomechanical behaviour highly dependent on temperature as well as four characteristic temperatures: $M_{s}$ (Martensite start) initial temperature to form martensite; $M_{f}$ (Martensite finish) final temperature to form martensite; $A_{s}$ (Austenite start) initial temperature to form austenite; $A_{f}$ (Austenite finish) final temperature to form austenite [5]. Notably, in both thermomechanical behaviour and many other applications measuring and quantifying the temperature of the shape memory elementis fundamental [6].

Depending on the SMAs' application, the conventional methods for measuring temperature such as thermocouples sometimes do not provide adequate results, mainly due to the effects of contact resistance loss. Alternatively, thermography is a technique that has been utilised with many advantages when contrasted to conventional methods for measuring temperature inasmuch as it allows superficial temperature variations to be determined from a distance and contactless [7-8].

Even though thermography is the most adequate technique to quantify temperature variations remotely, the results obtained through that method are highly dependent on various physical factors related to radiant properties of material, mainly thermal emissivity [9]. Therefore, knowing the emissivity is necessary. The aim of this project is to analyse the variation caused by temperature in total hemispheric emissivity of a shape memory alloy $\left(\mathrm{Ni}_{55} \mathrm{Ti}_{45}\right)$. The first part of the study, which presented preliminary experimental results, has already been published [10]. The following work is a correspondent investigation.

\section{Materials and Methods}

\subsection{Samples}

For this study, we utilized two samples of NiTi alloy with nominal composition of $55 \%$ in Ni weight supplied by Nemesis Technology. The samples were produced and prepared in accordance with JIS A 1423 (Simplified test method for emissivity by Infrared Radio Meter) with cylindrical shape [11]. We opted for that format due to difficulties in the machining process, among which its hardness (66.84 HRA) stands out, as well as the existence of data showing that the emissivity of the cylinder-shaped SMA was obtained through thermography in similar conditions [12]. Moreover, cutting the samples can create superficial tensions that can eventually result in martensitic transformations of the material [1314]. The cuts $A_{1}$ and $A_{2}$ were made with a precision cut-off machine (Struers Secotom-15) in low-speed conditions (0.005 $\mathrm{mm} / \mathrm{s}$ ) with around $10 \mathrm{~mm}$ diameter and $100 \mathrm{~mm}$ length, being continuously cooled by a cooling fluid. Afterwards, the samples received additional care such as ultrasonic cleaning bath during 20 minutes in a $\left(\mathrm{CH}_{3}\right)_{2} \mathrm{CO}$ solution.

Table 1 exposes the phase transformation temperatures of the alloy measured by a DSC-8500 and Pyris ${ }^{\circledR}$ Perkin Elmer software with heating and cooling rates controlled at $20^{\circ} \mathrm{C} /$ minute under continuous nitrogen gas flow. The 
general alloy composition, "as-received" obtained by EDX-720, is presented on Table 2. A small quantity of Al, Fe, Ca and $\mathrm{Si}$ is present.

Table 1. Phase transformation temperatures.

\begin{tabular}{|l|c|c|c|c|}
\hline Sample $\mathrm{Ni}_{55} \mathrm{Ti}_{45}$ & $\mathrm{~A}_{\mathrm{s}}\left({ }^{\circ} \mathrm{C}\right)$ & $\mathrm{A}_{\mathrm{f}}\left({ }^{\circ} \mathrm{C}\right)$ & $\mathrm{M}_{\mathrm{s}}\left({ }^{\circ} \mathrm{C}\right)$ & $\mathrm{M}_{\mathrm{f}}\left({ }^{\circ} \mathrm{C}\right)$ \\
\hline $\mathrm{A}_{1}$ & 57.01 & 74.80 & 41.41 & 15.62 \\
\hline $\mathrm{A}_{2}$ & 57.00 & 75.10 & 41.20 & 15.30 \\
\hline
\end{tabular}

Table 2. Chemical composition of the NiTi alloy "as-received".

\begin{tabular}{|l|c|c|c|c|c|c|}
\hline Chemical content & $\mathrm{Ni}$ & $\mathrm{Ti}$ & $\mathrm{Al}$ & $\mathrm{Fe}$ & $\mathrm{Ca}$ & $\mathrm{Si}$ \\
\hline$\%$ wt. & 55.408 & 43.888 & 0.295 & 0.157 & 0.143 & 0.109 \\
\hline
\end{tabular}

The calorimetric analysis showed that each sample is partially martensitic at ambient temperature. Thus, roughness was measured at stable ambient temperature. Arithmetic average surface roughness (Ra), stands for the root mean square $(\mathrm{Rq})$ and for the maximum peak to valley distance in profile (Rt) were measured for each sample. Table 3 shows the roughness properties for the analyses carried out at ambient temperature.

Table 3. Sample roughness at ambient temperature.

\begin{tabular}{|l|c|c|c|}
\hline Sample $25^{\circ} \mathrm{C}$ & $\mathrm{R}_{\mathrm{a}}$ & $\mathrm{R}_{\mathrm{t}}$ & $\mathrm{R}_{\mathrm{q}}$ \\
\hline $\mathrm{A}_{1}$ & 0.761 & 5.41 & 0,968 \\
\hline $\mathrm{A}_{2}$ & 0.760 & 5.36 & 0.960 \\
\hline
\end{tabular}

At ambient temperature, around $25^{\circ} \mathrm{C}$, samples $\mathrm{A}_{1}$ and $\mathrm{A}_{2}$ showed very similar superficial characteristics.

\subsection{Emissivity measurements}

The emissivity of samples $A_{1}$ and $A_{2}$ as a function of temperature was measured by an experimental apparatus developed for that purpose. Figure 1 shows the device, built in accordance with JIS A 1423 (Simplified test method for emissivity by Infrared Radio Meter) and ASTM E1933-99 (Standard Test Methods for Measuring and Compensating for Emissivity Using Infrared Imaging Radiometers) [15]. It carries out measurements through direct or indirect calorimetric and radiometric methods for temperatures that vary from 25 to $100^{\circ} \mathrm{C}$, and for wavelengths between 8 and $14 \mu \mathrm{m}$ under vacuum. In order to measure total hemispheric emissivity (integrated in $180^{\circ}$ from $\theta=-90^{\circ}$ to $\theta=90^{\circ}$ ), the apparatus uses an active source and an infrared detector (IR) connected to the controlling block through optical fibre cables. When the IR source is on, it has a commutation frequency that varies from 0.5 to $20 \mathrm{~Hz}$. Then a microcontroller stores the data collected from its analog-to-digital converter, called $\mathrm{ADCl}$ and $\mathrm{ADCl}$, in $\mathrm{E}^{2} \mathrm{PROM}$ memory. After that, the processer calculates the difference between the IR radiation in ADCI/ADCII and the radiation received during IR transmitter variation - converters called ADCIII and ADCIV. Therefore, emission rate is obtained through the equation (1).

$$
\text { Epsout }=1-\frac{(A D C I I I-A D C I V)}{(A D C I-A D C I I)} * f m-f R
$$

where $\mathrm{fm}$ is the reflection index and $F_{R}$ is the hemispheric correction factor.

The configuration applied permitted us to obtain the emissivity dependence angle (angle between emission direction and normal on the sample surface) in relation to its inclination. The sample was placed on a support and a Joule effect heater device was used for heating it. During the testing, when the sample emissivity value changes, the new value is calculated and transferred through an analogical output $0-10$ volts to a software. Thus, the signal is conditioned to a range where: $0 \vee \varepsilon=0.100$ and $10 \vee \varepsilon=1.00$. 


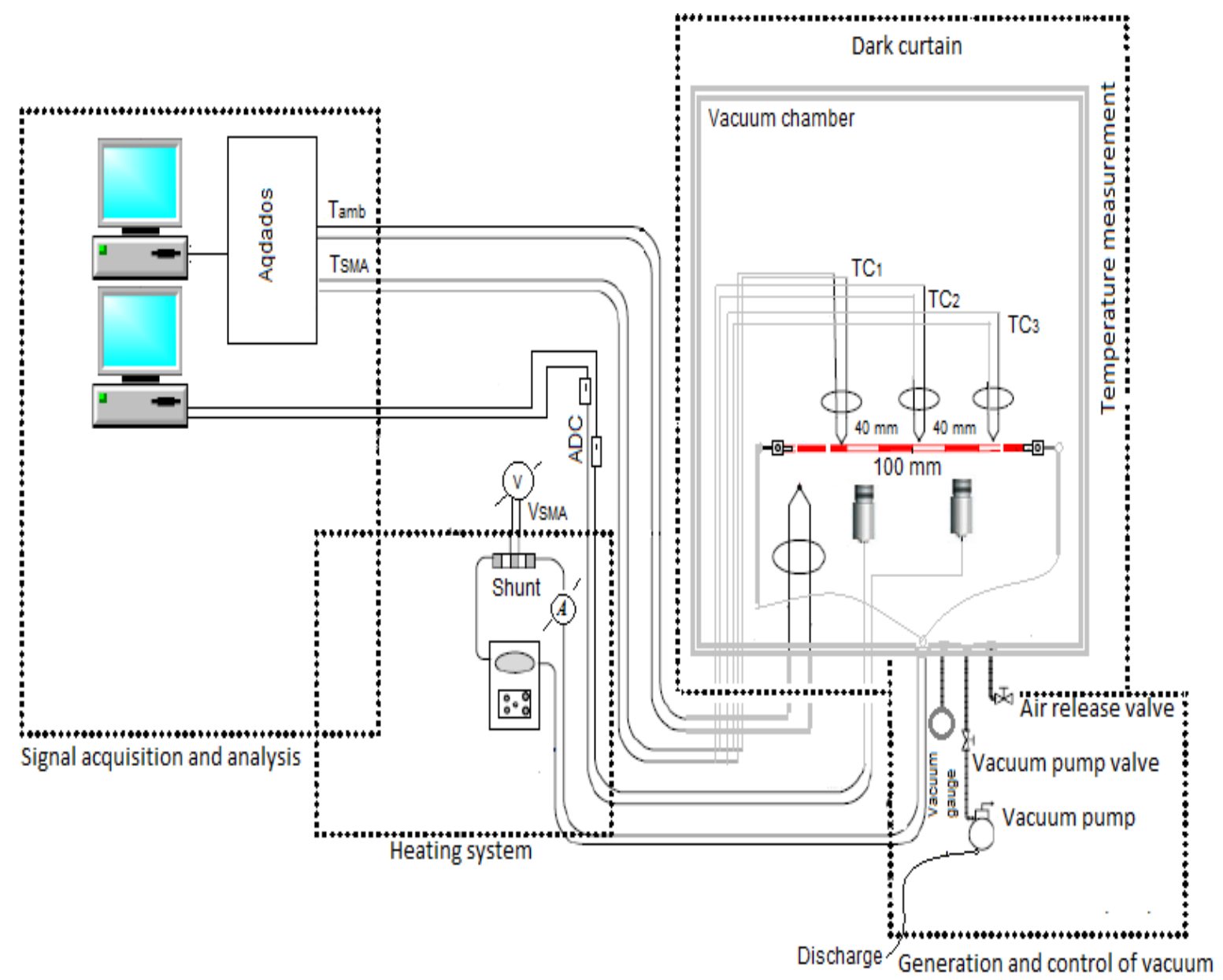

Fig. 1. Schematic of apparatus developed for measuring emissivity.

Three type $\mathrm{K}$ thermocouples welded to the sample surface, placed away from the visualisation area of the IR sensors, measured temperature. The average of temperatures was called $T_{1}$. Three PTC sensors were utilised to obtain the temperature inside the vacuum bell jar. The average of temperatures here was named $T_{2}$. Pressure inside the vacuum bell jar is kept at $3 \times 10^{-3} \mathrm{~Pa}$ during the experiments. Under these conditions, assuming that the heat loss throughout the sample due to conduction and convection are insignificant when compared to the loss caused by radiation, the emissivity is [16]:

$$
\boldsymbol{E}_{1}=\frac{Q}{\sigma \mathrm{A}_{1}\left(T_{1}^{4}-\mathrm{T}_{2}^{4}\right)}
$$

where $\varepsilon_{1}$ is the total hemispheric emissivity of the sample in $T_{1} ; Q=I V(W)$ is the electric power obtained in the sample; $\sigma$ is the Stefan-Boltzmann constant; $A_{1}$ is the surface area where the tests were carried out and $T_{1}$ and $T_{2}$ are the temperatures of the given surface area and the wall under vacuum respectively.

The total hemispheric emissivity in Equation (2) is a function of area $A_{1}$, temperatures $T_{1}$ and $T_{2}$ and electric power calculated through the voltage drop, $\mathrm{V}$, and current I [17]. The function is:

$$
\varepsilon=F\left(T_{1}, T_{2}, \mathrm{~A}_{1}, Q\right)
$$

The total hemispheric emissivity uncertainty is measured by:

$$
\frac{\Delta \varepsilon}{\varepsilon}=\left[\left(\frac{\partial \ln F}{\partial S}\right)^{2}(\Delta S)^{2}+\left(\frac{\partial \ln F}{\partial T^{1}}\right)^{2}\left(\Delta T_{1}\right)^{2}\left(\frac{\partial \ln F}{\partial T_{2}}\right)^{2}\left(\Delta T_{2}\right)^{2}+\left(\frac{\partial \ln F}{\partial U}\right)^{2}(\Delta U)^{2}+\left(\frac{\partial \ln F}{\partial I}\right)^{2}(\Delta I)^{2}\right]^{1 / 2}
$$




\subsection{1/qirt.2016.018}

\section{Experimental Results and Discussion}

The total hemispheric emissivity of the samples $A_{1}$ and $A_{2}$ was measured from 25 to $100^{\circ} \mathrm{C}$ approximately using the apparatus describe in section 2.2 and starting in total martensitic state. The curves and analyses were carried out at MATLAB [18]. Figure 2 shows total hemispheric emissivity curves as a function of temperature. Data reveal the average of direct radiometric measurements for the samples $A_{1}$ (Figure 2a) and $A_{2}$ (Figure 2b). The results in Figure 2 show that the total hemispheric emissivity of the samples $A_{1}$ and $A_{2}$ during heating is almost constant for temperatures varying from 26 to $65^{\circ} \mathrm{C}$ and decreases between temperatures $A_{s}$ and $A_{f}$ with temperature rise. The average emissivity variation of the sample $A_{1}$ between temperatures $A_{s}$ and $A_{f}$ was around $19 \%$ in direct measurements (Figure $2 a$ ) and also $19 \%$ in indirect measurements (Figure $3 a$ ). For the sample $A_{2}$, the average emissivity variation between temperatures $A_{s}$ and $A_{f}$ was around $15.2 \%$ in direct measurements (Figure $2 \mathrm{~b}$ ) and $6.1 \%$ in indirect measurements (Figure $3 b$ ).

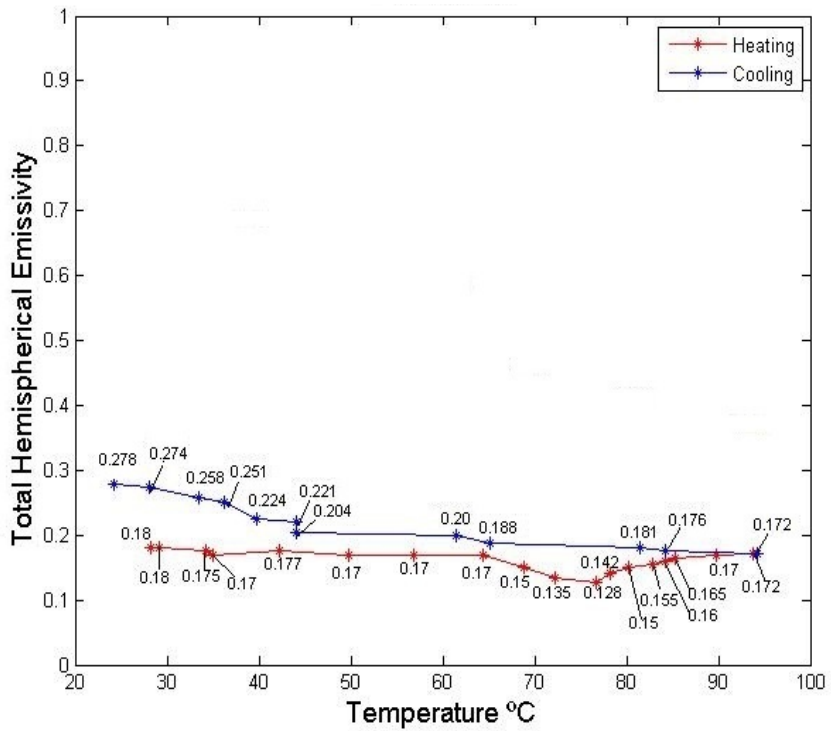

a. sample $A_{1}$

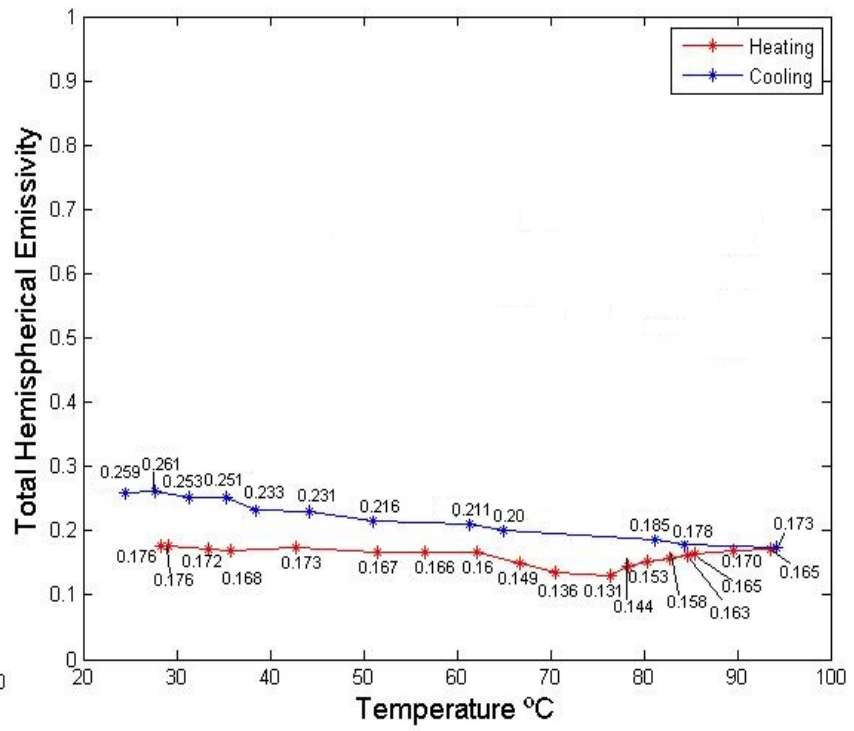

b. sample $A_{2}$

Fig. 2. Total hemispheric emissivity curves registered in direct measurements.

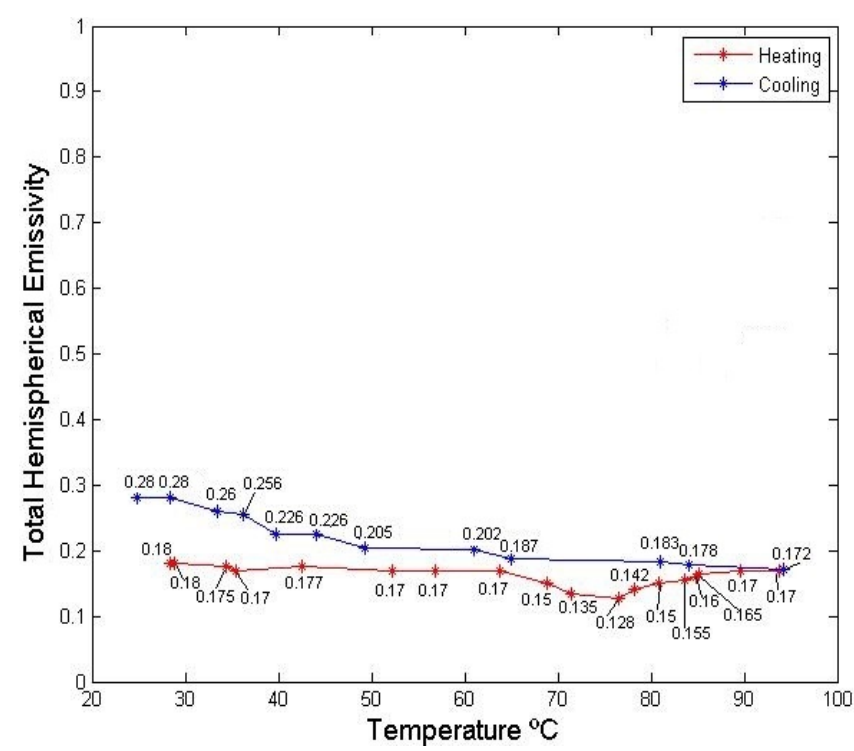

a. sample $A_{1}$

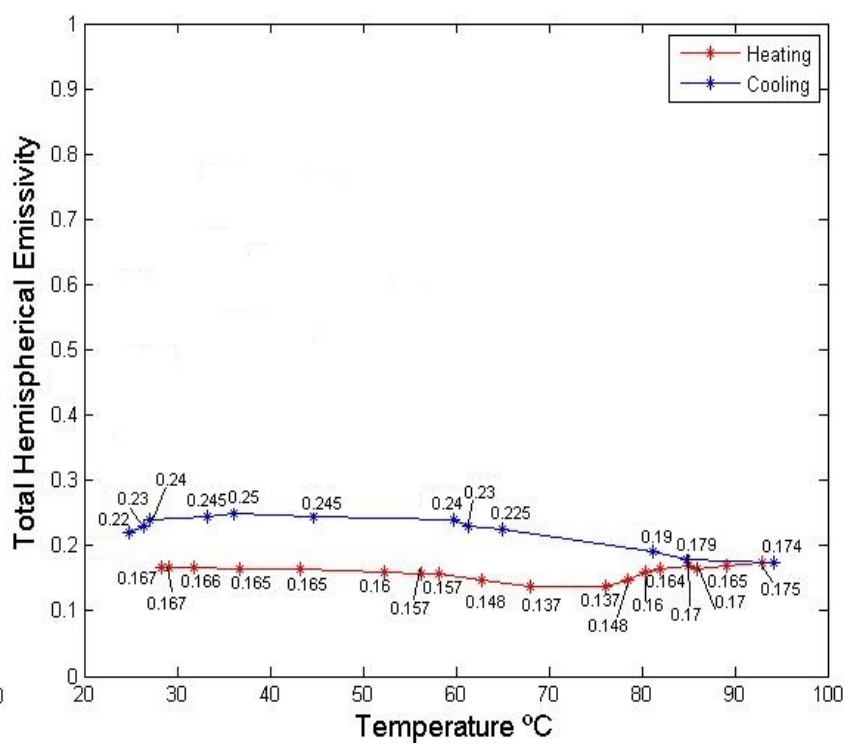

b sample $\mathrm{A}_{2}$

Fig. 3. Total hemispheric emissivity curves registered in indirect measurements.

During the heating phase, emissivity decreased from 0.171 in martensitic phase to 0.155 in austenitic phase (Figure 2). Hemispheric emissivity variation can be explained theoretically and experimentally through the average roughness variation of the alloy - which is $0.760 \mu \mathrm{m}$ in martensitic phase and $0.821 \mu \mathrm{m}$ in austenitic phase [19]. At 


\subsection{1/qirt.2016.018}

temperature $A_{s}$ emissivity starts to decrease due to the reduction of martensitic relief and emissivity directions since each surface protuberance caused by martensitic variant has its own normal direction [20]. At temperature $A_{f}$ martensitic relieves tend to completely disappear, minimizing emissivity. At temperature over $A_{f}$ emissivity increases again probably as a result of temperature rise. During the cooling phase, emissivity behaviour is different, that is, emissivity values increase and starting with $M_{s}$ those values tend to increase more intensely.

Figure 4 shows the two manners of NiTi surface reflection. On the one hand, in martensitic state the sample surface behaves like a diffuse emitter and reflector, that is, there is a larger quantity of directions for emission to be radiated due to more significant roughness (Figure $4 \mathrm{~b}$ ). On the other hand, when the phase is totally austenitic (Figure $4 a)$ reflection is regular, keeping more parallelism during the incidence of rays and minimizing directions.

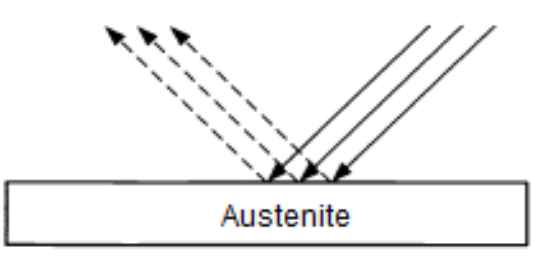

Heating

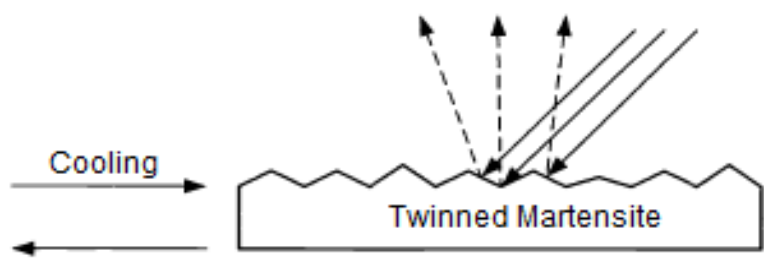

b Low temperature

a High temperature

Fig. 4. Representation of NiTi surface reflection [19].

Figure 5 shows emissivity curves superposition as a function of temperature during the heating phase (Figures 2 and 3 ) and Figure 6 shows the total hemispheric emissivity curve obtained through calorimetric measurements. The data of the Figure 6 curve refer to the average of values in sample $A_{1}$ and were calculated by the Equation (2).

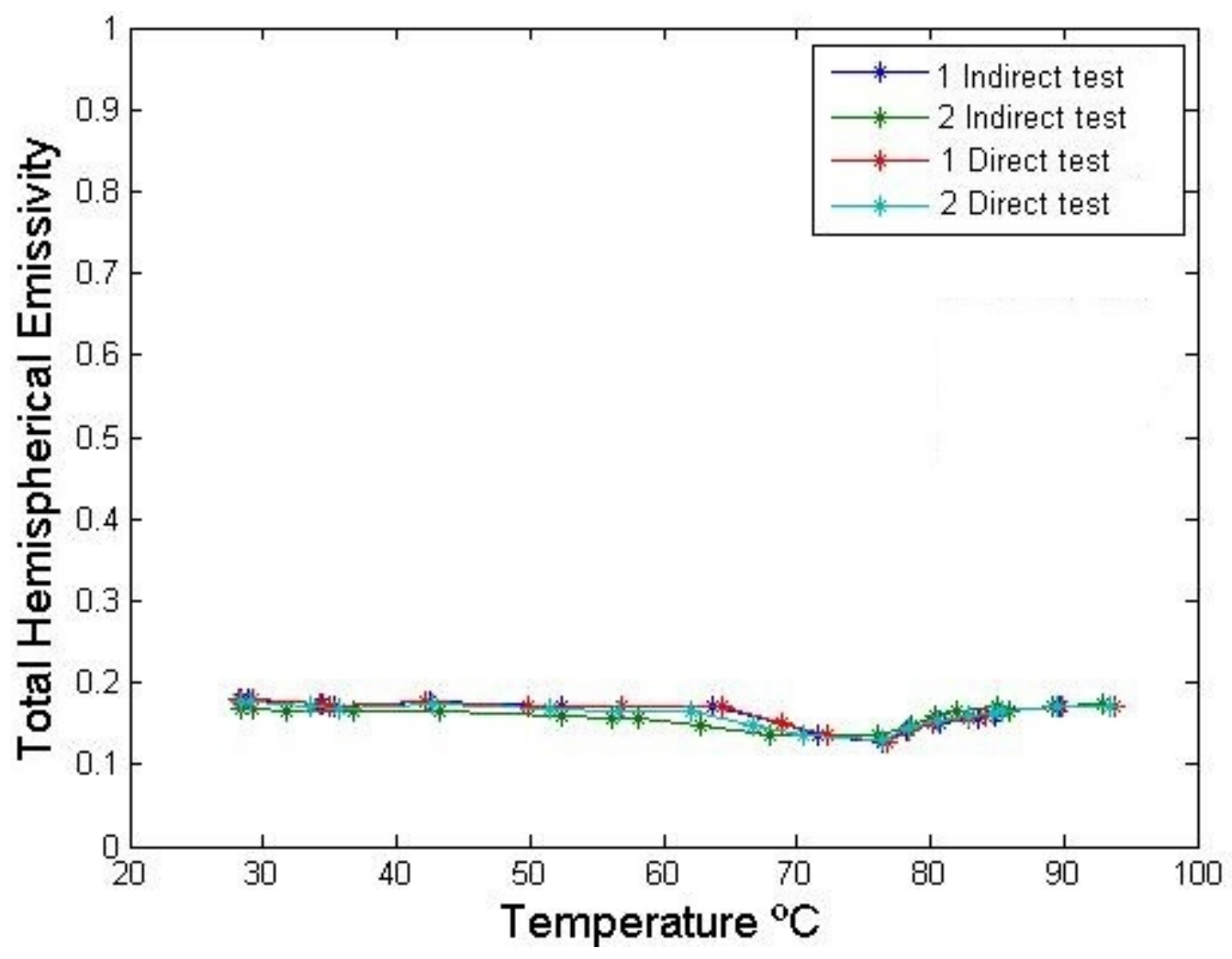

Fig. 5. Emissivity curves superposition versus temperature during heating phase (Figures 2 and 3). 


\subsection{1/qirt.2016.018}

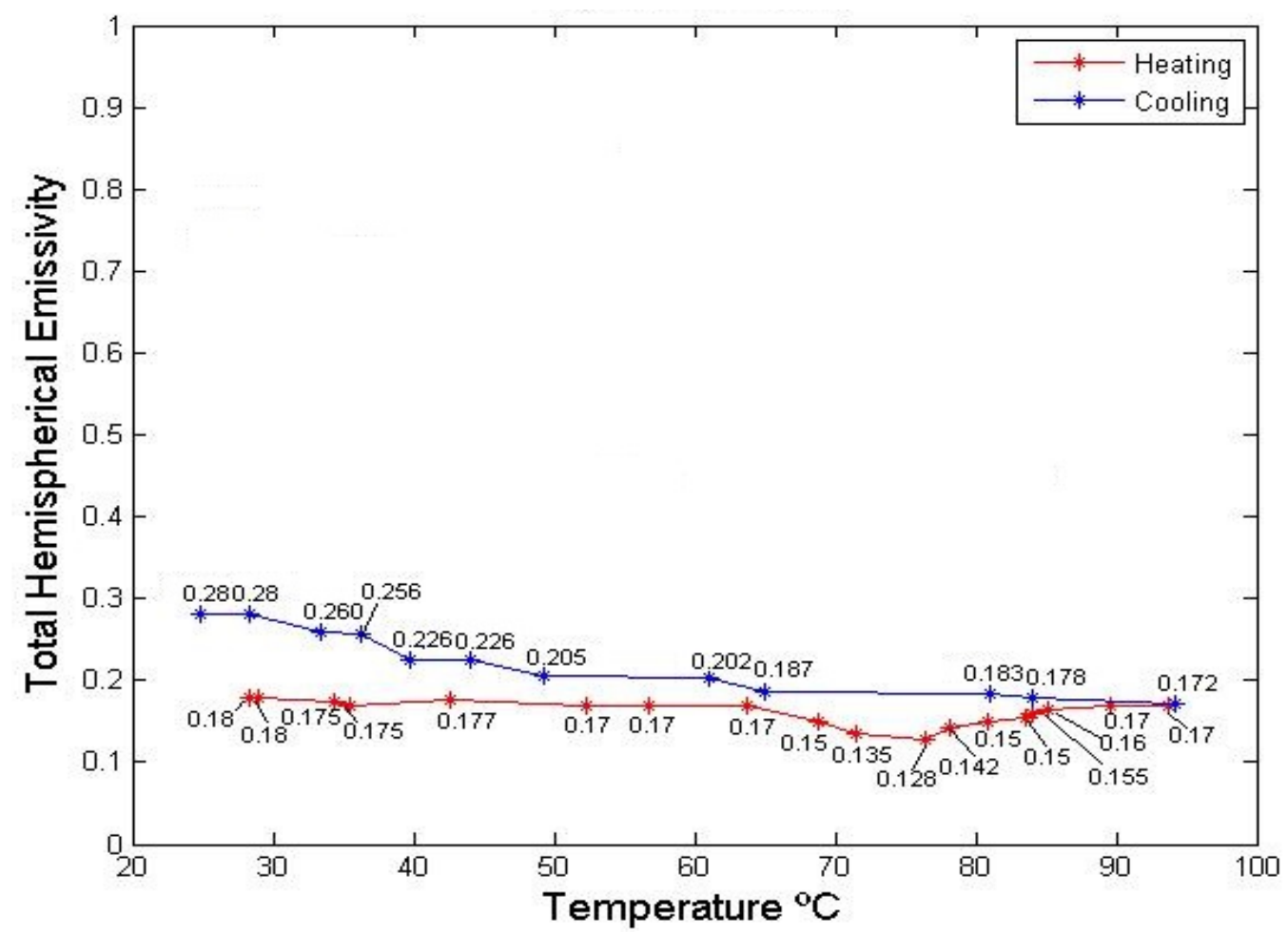

Fig. 6. Total hemispheric emissivity curve versus temperature of the sample $A_{1}$.

For the temperature range analysed, data reveal that the most expressive total hemispheric emissivity variation happens in phase change. Emissivity varies approximately $24 \%$ from $M_{s}$ at ambient temperature $\left(24^{\circ} \mathrm{C}\right)$. There is a correlation between emissivity variation and the error produced when temperature was measured if the emissivity is not corrected. That error is calculated by:

$$
T^{4}=\frac{E(t)}{\varepsilon \sigma},
$$

Replacing temperature and emissivity in the equation, we have:

$$
\frac{T_{1}^{4}}{T_{2}^{4}}=\frac{\frac{E(t)}{\varepsilon_{1} \sigma}}{\frac{E(t)}{\varepsilon_{2} \sigma}}
$$

where $T_{1}$ is the average temperature measured before adjusting emissivity; $T_{2}$ is the real temperature on the surface; $\varepsilon_{1}$ is the emissivity measured before the adjustment; and $\varepsilon_{2}$ is the real emissivity of the surface. The solution of the equation is:

$$
T_{2}=\sqrt[4]{\frac{\varepsilon_{1}}{\varepsilon_{2}}} T_{1}
$$

For emissivity experimental data in this work, we have:

$$
T_{2}=1,0377 T_{1}
$$




\subsection{1/qirt.2016.018}

Therefore, temperature $T_{1}$ at the final temperature for austenite formation $\left(\mathrm{A}_{\mathrm{f}}\right)$ read as $78.2^{\circ} \mathrm{C}$ is then corrected to $81.15^{\circ} \mathrm{C}$ with emissivity adjustment $\varepsilon_{2}$. Thus, $15 \%$ of emissivity variation corresponds to a reading error of approximately $3^{\circ} \mathrm{C}$ without emissivity correction.

\section{Conclusions}

The total hemispheric emissivity of two SMA alloys was experimentally analysed as a function of temperature through diverse methods. We could understand that global average hemispheric emissivity showed variations of around $9 \%$ between martensitic and totally austenitic states. Preliminary analysis of superficial characteristics of the alloy reveals that the variation occurred mainly as a result of surface relief associated with martensitic phase transformation.

\section{Acknowledgments}

The author thanks FAP-DF for the financial support for the development of the present work. 


\subsection{1/qirt.2016.018}

\section{REFERENCES}

[1] Srinivasan, A. V. and Mc Farland, D. M., Smart Structures, Analysis and Design, Cambridge University Press, 2001.

[2] Eggeler G., Hornbogen E., Yawny A., Heckmann A., Wagner M., Materials Science and Engineering A 378 (2004) 24-33.

[3] Otsuka, K.; Wayman, C. M. Mechanism of Shape Memory Effect and Superelasticity. Cambridge University Press, Cambridge, 1998, p. 27-48.

[4] Delaurentis, K.J., Mavroidis, C., Pfeiffe, C., Development of a Shape Memory Alloy Actuated Robotic Hand, (2000).

[5] Otsuka K., Wayman, C. M.; editors. Shape Memory Materials, Cambridge University Press (Cambridge, 1998).

[6] Herve, P.; Cedelle, J.; Negreanu, I. Infrared technique for simultaneous determination of temperature and emissivity. Infrared Physics \& Technology vol. 55 pp 1-10, 2012.

[7] Marinetti, S.; Cesaratto, P.G. Emissivity estimation for accurate quantitative thermography. NDT \& E International vol. 51 pp 127-134, 2012.

[8] E.Pieczyska, H. Tobushi. Temperature visualisation of shape memory alloy various behavior. QIRT 2010 Conference, Québec, Canada. 27-30, July 2010.

[9] L.Del Campo, Pérez-Sáez R.B., González-Fernández L, Esquisabel X, Fernández I, González-Martín P. Emissivity measurements on aeronautical alloys. J Alloys Compd; 489:482-7, 2010.

[10] Da Silva, T.C., Da Silva, E.P. Experimental evaluation of the emissivity of a NiTi alloy. Proceedings of the International Conference on Shape Memory and Superelastic Technologies, SMST-2015. May 18-22, 2015, Chipping Norton, Oxforshire, UK.

[11] JIS A 1423, (1983), Simplified Test Method for Emissivity by Infrared Radio Meter, (Reaffirmed 1988). Japanese Standards Association, 1983.

[12] Huilong, M. A. Thermal Modeling of Shape Memory Alloys Wire Actuators for Automotive Applications. Master Degree, Department of Mechanical Engineering, University of Waterloo, Ontario, Canada, 177p. 2010.

[13] K. Escher and M. Hühner, Metallographical Preparation of NiTi Shape Memory Alloys. Prakt. Metallogr., 1990, 27(5), p 231-235.

[14] M. Pohl, C. Hebing, J. Frenzel, "Electrolytic processing of NiTi shape memory alloys", Vol. 378 (2004), 191-199. [Materials Science and Engineering: A].

[15] ASTM E1933-99. Standard test methods for measuring and compensating for reflected temperature using infrared imaging radiometers; 10.1520/E1933-14 (2014).

[16] T.R. Fu, P. Tan, C.H. Pang, A steady-state measurement system for total hemispherical emissivity, Meas. Sci. Technol. 23 (2012). 025006.1-10.

[17] T.R. Fu, P. Tan, C.H. Pang, Total hemispherical radiation properties of oxidized nickel at high temperatures, Corrosion Science 83 (2014) 272-280.

[18] MATLAB R2011b on line documentation. The MathWorks. /www.mathworks.com/helpS; 2011.

[19] Huang, W. M.; Zhang, W. H.; Gao, X. Y. Micro Mirror Based on Surface Relief Phenomenon in Shape Memory Alloys. SPIE Vol. 4918, 2002, pp 155-161, 2002.

[20] Huang, W.M.; Zhang, W.H. Surface Relief Phenomenon in a NiTi Shape Memory Alloy Rod. SPIE Photonics: Design, Technology, and Packagin vol. 5277 pp 198-205, 2004. 